Military Technical College

Kobry El-Kobbah,

Cairo, Egypt.

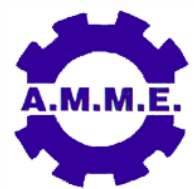

$16^{\text {th }}$ International Conference
on Applied Mechanics and
Mechanical Engineering.

\title{
MULTI OBJECTIVE OPTIMIZATION OF PRESSURE CYCLE OF ABS INJECTION MOLDING PROCESS
}

\author{
M. M. Radwan ${ }^{\star}$, A. M. Youssef ${ }^{\dagger}$, K. T. Ismael ${ }^{\ddagger}$ and M. Merdan ${ }^{\S}$
}

\begin{abstract}
Injection molding is defined as a cyclic process for producing identical products from a mold and it is the most widely used polymer processing operation. The main advantage of this process is the capacity of repetitively fabricating parts. Certain challenges face this process in order to get a defect free product. The control of the cavity pressure is important for maintaining the quality of the plastic product. The common practice in industry is to have a fixed value for the pressure during the filling phase and also during the packing phase of the process. This may lead to the introduction of defects in the final product. This paper presents a mathematical model and experimental verification of a strategy to control the cavity pressure profile during the filling and the packing phases to minimize the flow marks, warpage and shrinkage for an ABS injection molded product. For the packing phase, the efficient frontier method is used to obtain the optimum pressure for minimizing the combination effect between the warpage and the shrinkage. This may be used as a tool for weighing the behavior of these two defects with the variation of the packing pressure. The results showed the effectiveness of the mathematical model used for predicting the filling and pressures to minimize the investigated defects.
\end{abstract}

\section{KEY WORDS}

Injection molding process, Cavity pressure control, Elimination of the plastic product defects.

\footnotetext{
* Mech. Eng., Ministry of Military Production, Egypt, Email: eng.m_radwan@yahoo.com.

$\dagger \quad$ Egyptian armed forces

‡ Egyptian armed forces

$\S$ Modern Academy-Maadi, Cairo
} 


\section{INTRODUCTION}

Among all the processing methods of polymers, injection molding process is one of the most important, versatile, widespread, and cost-effective operations in the mass production of complex plastic parts. This process involves melting plastic pellets and shaping this melt under high pressure and temperature in a closed mold to produce the plastic component with the required specifications [1]. The pressure of the melt (cavity pressure) that enters from the gate to the cavity plays an important role in the process because it is a direct indication of how the polymer melt behaves in the process and its effect on the quality of the part [2], [3], [4].

\section{CAVITY PRESSURE PROFILE}

For the filling phase the clamp unit keeps the empty mold closed and the screw moves forward as a ram and forces the melt into the mold cavity, the pressure used for filling the mold cavity is called injection pressure. At this stage the cavity filled with about $95 \%$ of the cavity space. The packing pressure holds for certain time to compensate the shrinkage of the plastic. Regardless of the shape of the cavity, the pressure in the cavity decreases monotonically from the maximum pressure at the point of injection to atmospheric pressure at the melt front as shown in Figure 1.

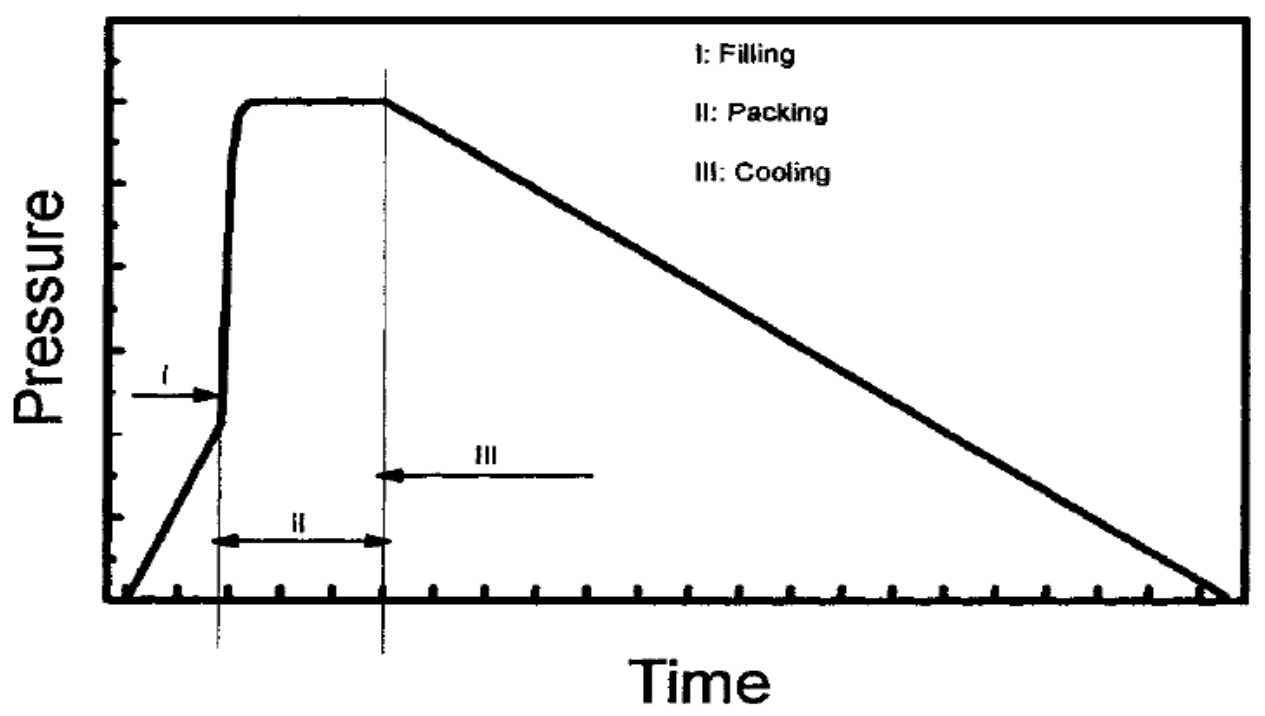

Figure 1. Cavity Pressure profile during an injection molding cycle.

\section{MATERIALS AND MACHINE}

The injection molding machine used in this investigation is; Jon Way 250SD with clamping force 250 ton, shot size 821 grams. The material under investigation is Acrylonitrile Butadiene Styrene ABS provided by Taita Chemical Company. 


\section{EVALUATION OF THE INJECTION PRESSURE}

In the injection process, the flow rate must be constant for all parts of the mold in order not to get variable filling times or splashing. This would also introduce defects in the final products as well. The most common way is to calculate the maximum injection pressure at the maximum cross sectional area and apply this pressure across all the cavity space. This way may give acceptable injected products but do not use optimum pressure suitable for the current cross section being filled. It also consumes more power of the machine.

While entering the molten plastic into the cavity space, the pressure inside varies according to the cross sections that may be increased and in the same space may decrease. The objective is maintaining a constant flow rate during the filling stage across all cross sections of the cavity space to avoid any problem occurrence during filling.

The isothermal pressure drop for a disk-shaped cavity is given as follows [5]:

$$
\mathrm{P}=\frac{K_{r}}{\left(1-n_{r}\right) 10^{5}}\left[\frac{360 \cdot \mathrm{Q} \cdot\left(1+2 \cdot n_{r}\right)}{\mathrm{N} \cdot \Theta \cdot 4 \pi \cdot n_{r} \cdot \mathrm{r} \cdot \mathrm{b}^{2}}\right]^{n r} \cdot\left(\frac{r}{b}\right)
$$

where:

$n_{r} \quad$ The reciprocal of the power law exponent $(=0.2565)$,

$\mathrm{K}_{\mathrm{r}} \quad$ Constant corresponding to melt viscosity $\left(=3.05 \times 10^{4}\right)$,

Q' Constant injection rate $\left(\mathrm{cm}^{3} / \mathrm{s}\right)$,

b Half thickness of the disc $(\mathrm{cm})$,

$r \quad$ Radius of the disc $(\mathrm{cm})$,

$\mathrm{N} \quad$ Number of gates, and

$\Theta \quad$ Melt flow angle.

Equation (1) correlates between volumetric flow rate, cross section area, and thickness with the pressure in the cavity. This equation is modified to be suit the variable pressure investigation as follows;

$$
\mathrm{P}=\frac{K_{r}}{\left(1-n_{r}\right) 10^{5}}\left[\frac{360 \cdot \mathrm{Q} \cdot\left(1+2 \cdot n_{r}\right)}{\mathrm{N} \cdot \Theta \cdot 4 \pi \cdot n_{r} \cdot \mathrm{X} \cdot \mathrm{b}^{2}}\right]^{n r} \cdot\left(\frac{x}{b}\right)
$$

As shown in Figure 2, equation (2) will be modified to be a function of the distance (s) instead of $(x)$ as follows.

$$
\mathrm{P}=\frac{K_{r}}{\left(1-n_{r}\right) \times 10^{5}}\left[\frac{360 \times \mathrm{Q} \times\left(1+2 . n_{r}\right)}{\mathrm{N} \times \Theta \times 4 \pi \times n_{r} \times \sqrt{\mathrm{s}(2 \mathrm{R}-\mathrm{s})} \times \mathrm{b}^{2}}\right]^{n r}\left(\frac{\sqrt{\mathrm{s}(2 \mathrm{R}-\mathrm{s})}}{b}\right)
$$

where $s$ is the filling distance from the gate and it is variable. 


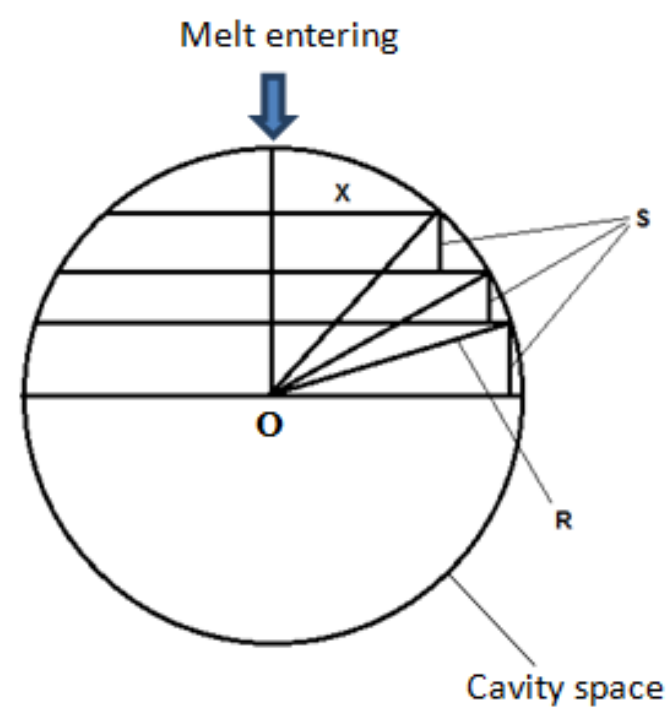

Figure 2. Designation of cavity dimensions

According to the machine settings used in this study, the injection process can be controlled for six pressure values, so the cavity space will be divided into six sectors starting from the gate $(\mathrm{I})$.

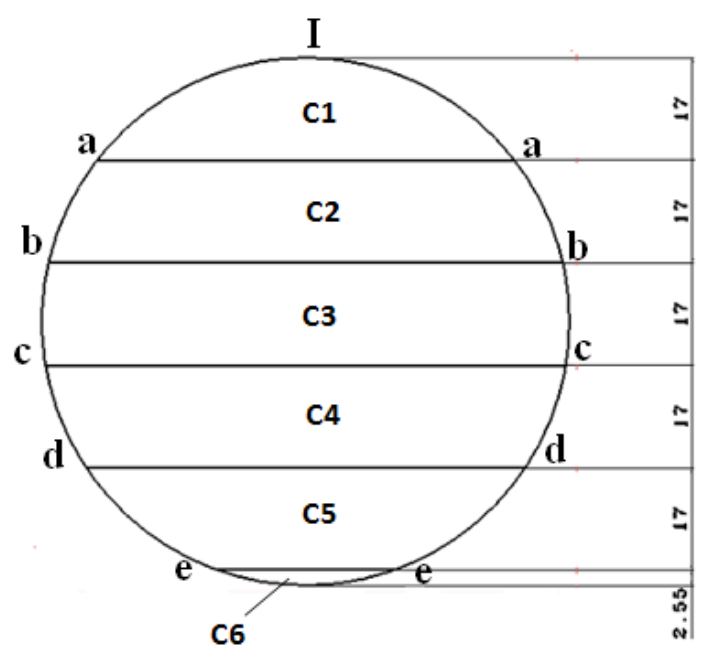

Figure 3. Sectioning of the cavity.

From Figure 3, the cavity pressure [MPa] will be as listed in the table below:

\begin{tabular}{|l|l|l|l|l|l|}
\hline $\mathbf{P}_{\mathbf{1}}$ & $\mathbf{P}_{\mathbf{2}}$ & $\mathbf{P}_{\mathbf{3}}$ & $\mathbf{P}_{\mathbf{4}}$ & $\mathbf{P}_{\mathbf{5}}$ & $\mathbf{P}_{\mathbf{6}}$ \\
\hline 34 & 39 & 40 & 40 & 35 & 19 \\
\hline
\end{tabular}

The injection pressure calculated above will be divided over the intensification ratio, see Figure 4, to get the corresponding hydraulic pressure $\left(\mathbf{P}_{\mathbf{i h}}\right)[6]$. 


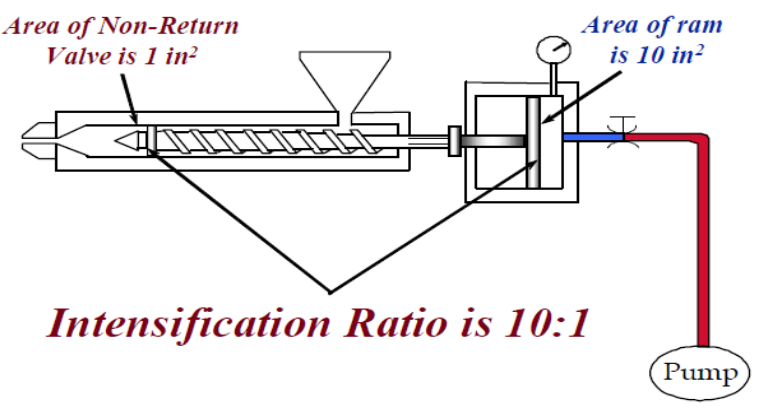

Figure 4. Intensification ratio calculation

The hydraulic pressure [MPa] will be:

\begin{tabular}{|c|c|c|c|c|c|}
\hline $\mathbf{P}_{1 \mathrm{~h}}$ & $\mathbf{P}_{2 h}$ & $\mathbf{P}_{3 h}$ & $\mathbf{P}_{4 h}$ & $P_{5 h}$ & $P_{6 h}$ \\
\hline 7 & 7,0 & $7, V$ & $\mathrm{T,V}$ & 7 & $r, Y$ \\
\hline
\end{tabular}

These values will be used on the machine pressure control.

\section{EVALUATION OF THE PACKING PRESSURE}

Packing pressure is an important parameter in affecting the warpage and the shrinkage defects [7], [8], [9], [10]. The aim is to try to solve or minimize the defects that occur in the packing phase. Shrinkage and warpage are the defects investigated in this study. The published work in this field studies the optimization of the packing pressure for elimination of a single defect at a time. In this work, a multi objective optimization for the minimization of both warpage and shrinkage is carried out. This investigation used published results that studied these two defects separately [11], [12]. By using efficient frontier method, these results were optimized to get the optimum values for the packing pressure.

\section{MULTI-OBJECTIVE OPTIMIZATION and EFFICIENT FRONTIER}

Multi-objective optimization method is an area of multiple criteria decision making, which is concerned with mathematical optimization problems involving more than one objective function to be optimized simultaneously [13]. The values used in solving this problem are shown for the shrinkage defect in Figure 5 and for warpage defect in Figure 6 


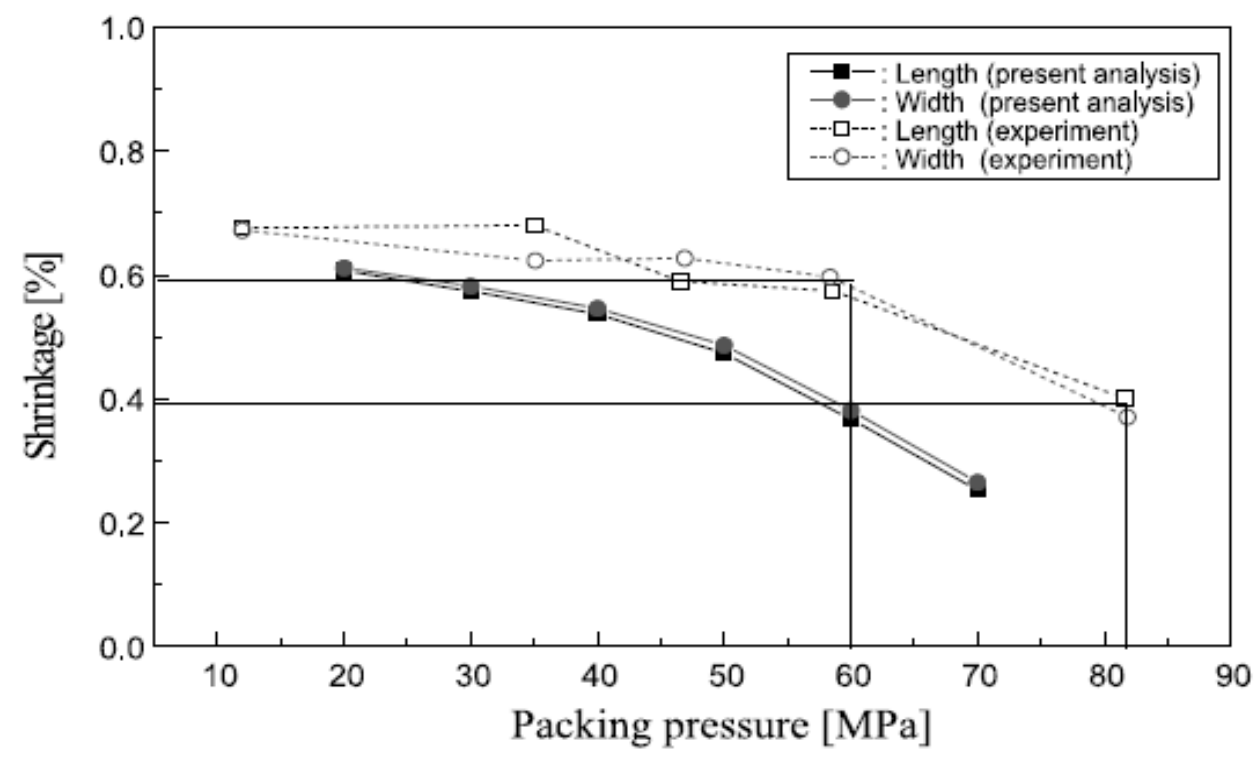

Figure 5. The effect of packing pressure on the shrinkage [11].

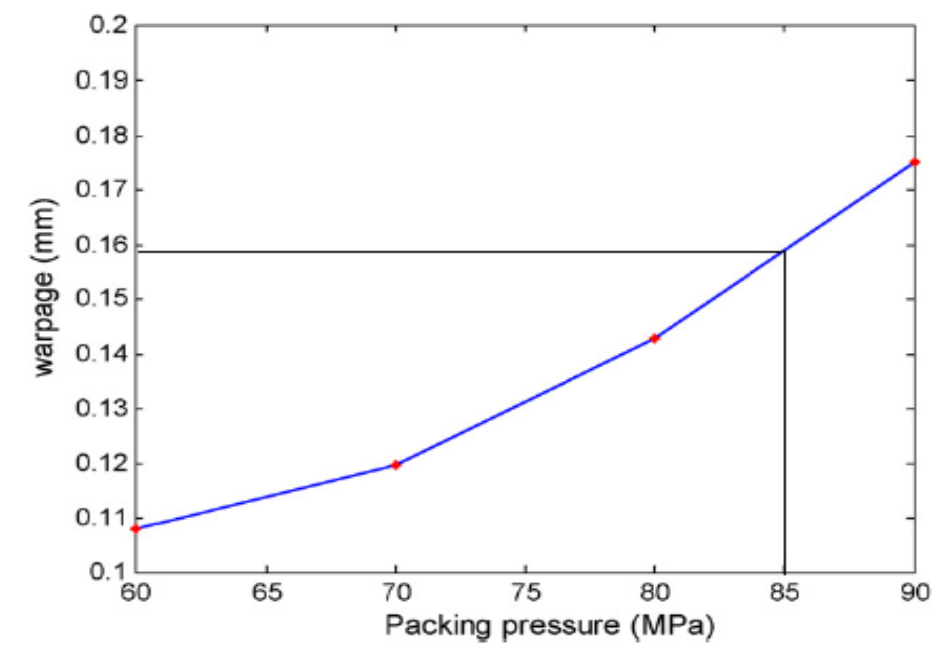

Figure 6. The effect of packing pressure on the warpage [12].

Normalizing the values from Figure 5. The effect of packing pressure on the shrinkage [11] and Figure 6 we get;

\begin{tabular}{|c|c||c|c|}
\hline Packing Pressure [ MPa ] & Shrinkage [\%] & Packing pressure [MPa] & Warpage [mm] \\
\hline 60 & 0.58 & 60 & 0.107 \\
\hline 65 & 0.52 & 65 & 0.114 \\
\hline 70 & 0.48 & 70 & 0.12 \\
\hline 75 & 0.46 & 75 & 0.13 \\
\hline 80 & 0.4 & 80 & 0.142 \\
\hline 85 & 0.38 & 85 & 0.158 \\
\hline
\end{tabular}

To find the efficient frontier, an analysis program was written in MATLAB to solve the multi-objective optimization problem. 
Using best fit method the relation was found to be polynomials of $3^{\text {rd }}$ order as follows:

1- Between packing pressure and shrinkage

$$
S=-1.1095 * 10^{-5} X^{3}+0.0024569 X^{2}-0.18809 X+5.4158
$$

2- Between packing pressure and warpage

$$
\mathbf{W}=1.4074^{*} 10^{-6} X^{3}-0.00025683 X^{2}+0.016863 X-0.28407
$$

where $\mathrm{S}$ is the shrinkage, $\mathrm{W}$ is the warpage and $\mathrm{X}$ is the packing pressure.

Figure 7 shows the results for the optimization problem. This can be used as a decision tool for weighing the cost of improving one goal over the other one. The points $(1,2,3)$ in the figure investigate the effect of changing packing pressure along the curve. Converting the value of the warpage and the shrinkage of along any point on the curve using equations (3) and (4), the corresponding packing pressures can be obtained obtained.

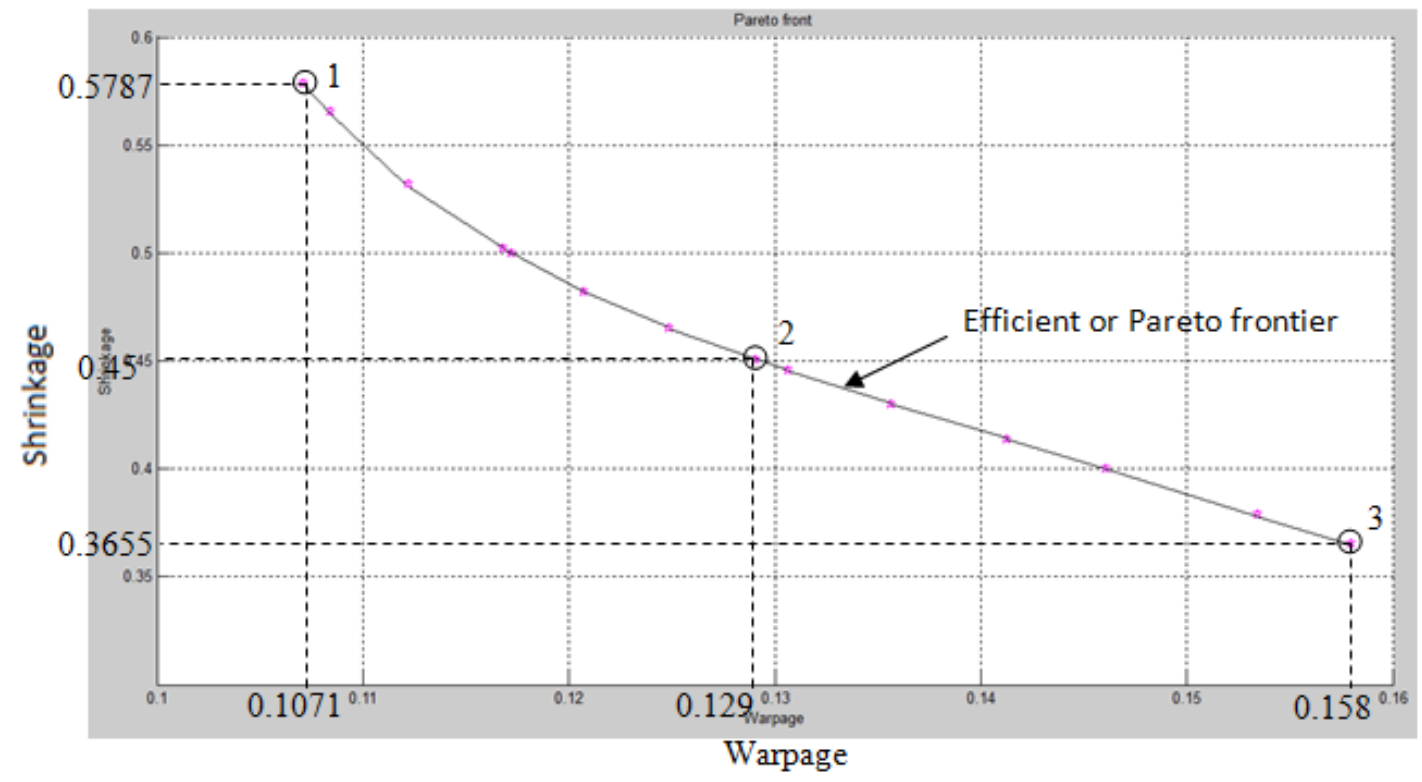

Figure 7. The efficient frontier results.

\section{THE SAMPLE SIZE AND NUMBER OF REPLICATIONS}

The experimental verification of the results required the determination of sample size and the repetition of an experimental condition so that the variability associated with the phenomenon can be estimated. Equation (5) determines the sample size required for this investigation [14].

$$
\mathrm{SS}=\left(\frac{Z_{\propto / 2}}{E}\right)^{2} \cdot \hat{p}(1-\hat{p})
$$


where $S S$ is the sample size, $Z_{\alpha / 2}$ is the $Z$ value for the required confidence level, $\hat{p}$ is the percentage of the sample that picks a particular answer, expressed as decimal, and $E$ is the confidence interval (also called margin of error), expressed as decimal.

Using equation (5) to compute the number of repetitions for each run and taking the average results when determining the defect.

$Z_{\alpha / 2}=1.96$ (for $95 \%$ confidence level).

$\hat{P}=0.5$ (a suggested in reference [14]).

The value of the margin of error will differ in this case. The first step is to compute the value of $(E)$ for each case and then find the sample size corresponding to the values of $(E)$.

For the shrinkage $\quad E=1-\frac{0.3655}{0.5787}=0.37$

$$
\begin{aligned}
& S S=\left(\frac{1.96}{0.37}\right)^{2 * 0.5(1-0.5)=7.02} \\
& S S=8 \text { runs }
\end{aligned}
$$

For the shrinkage $\quad E=1-\frac{0.1071}{0.158}=0.33$

$$
\begin{aligned}
& \mathrm{SS}=\left(\frac{1.96}{0.33}\right)^{2 *} 0.5(1-0.5)=8.8 \\
& \mathrm{SS}=9 \text { replications }
\end{aligned}
$$

Taking the maximum number of runs to be the greater number, so every run will be repeated 9 times.

\section{MEASURING INSTRUMENTS}

The un-aided eye was used to investigate flow marks on the surface of the product. The warpage was measured by digital dial gauge and shrinkage was measured using a digital micrometer Both instruments have the sensitivity up to $0.001 \mathrm{~mm}$.

\section{VERIFICATION OF THE FLOW MARKS}

Verifying the flow mark will be by checking the surface of the part for the existence of flow marks, cold shots, splashes and change of color. This inspection is performed by the un-aided eyes after cleaning the part surfaces. The acceptance criterion is the defects-free surface of the aforementioned defects. 


\section{MEASUREMENT OF THE WARPAGE}

In measuring the warpage, the flatness of the surface will be measured. For that, the surface of the sample, cf. Figure. 8 , is measured along four paths and each path was divided into four sectors.

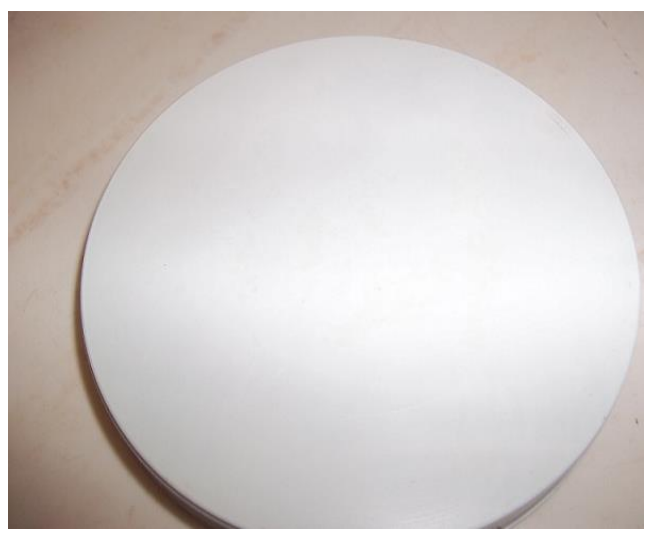

Figure 8. Picture of the surface of the sample.

The results of the average warpage for each sample group were:

\begin{tabular}{|c|c|}
\hline $\begin{array}{c}\text { Packing pressure } \\
{[\mathrm{MPa}]}\end{array}$ & Warpage $[\mathrm{mm}]$ \\
\hline 60 & 0.106 \\
\hline 75 & 0.144 \\
\hline 85 & 0.193 \\
\hline
\end{tabular}

\section{MEASUREMENT OF THE SHRINKAGE}

For measuring the shrinkage, the difference between the diameter of the samples and the mold diameter is measured. The values are measured by the digital micrometer at 4 different orientations for each sample and for every sample group. Then the average shrinkage for each sample group was:

\begin{tabular}{|c|c|}
\hline $\begin{array}{c}\text { Packing pressure } \\
{[\mathrm{MPa}]}\end{array}$ & shrinkage [\%] \\
\hline 60 & 0.239144317 \\
\hline 75 & 0.164272031 \\
\hline 85 & 0.089107067 \\
\hline
\end{tabular}

\section{DISCUSSION}

The visual inspections of the sample surface, showed that it has a good and smooth appearance and there is no change in the color of the part surface. No signs of the 
flow marks on the part surface after injecting the mold by using the optimized filling pressures.

For the warpage, it can be seen from Figure 9 that the warpage values increase with increasing the packing pressure. The two curves have the same trends. The difference between the predicted and the actual warpage within the working pressure range does not exceed $0.035 \mathrm{~mm}$.

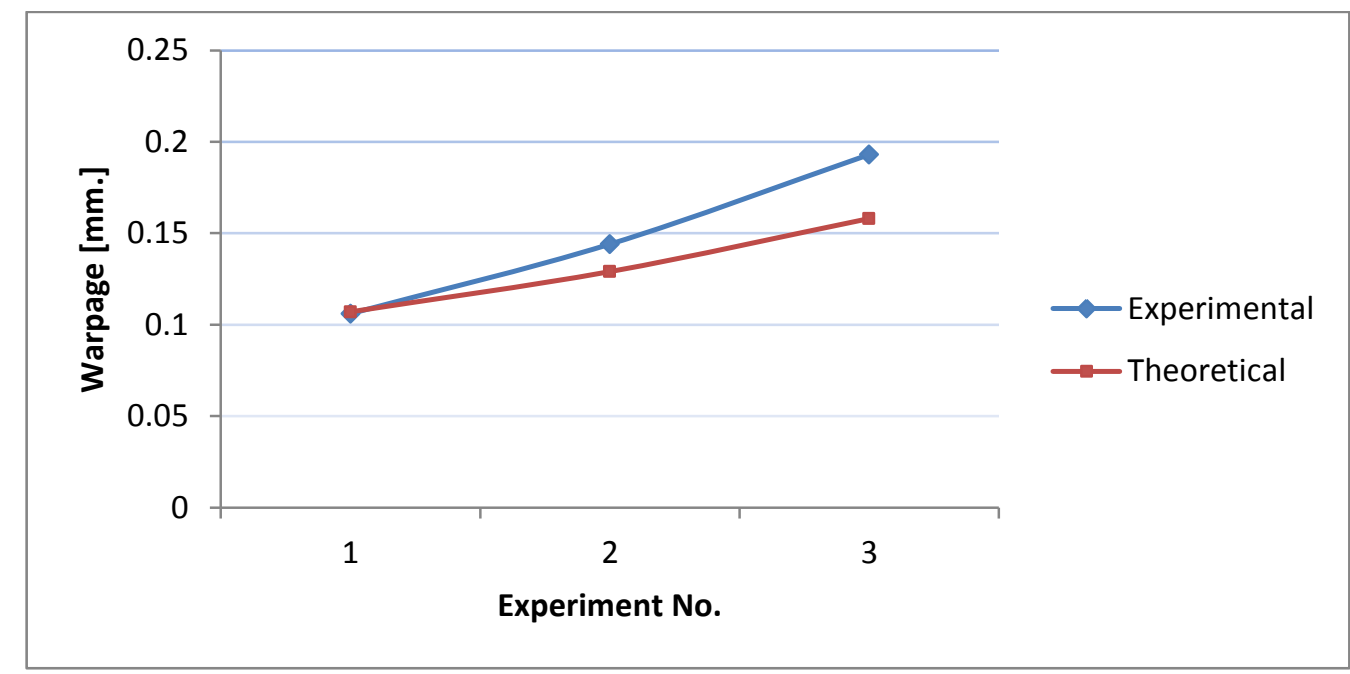

Figure 9. Experimental and theoretical warpage.

For the shrinkage, it can be seen from Figure 10 that its values decrease with increasing the packing pressures and also with the same trend of the predicted one. The values of the experimental results are better than the predicted ones with nearly the same difference. The difference between the two curves does not exceed $0.33 \%$.

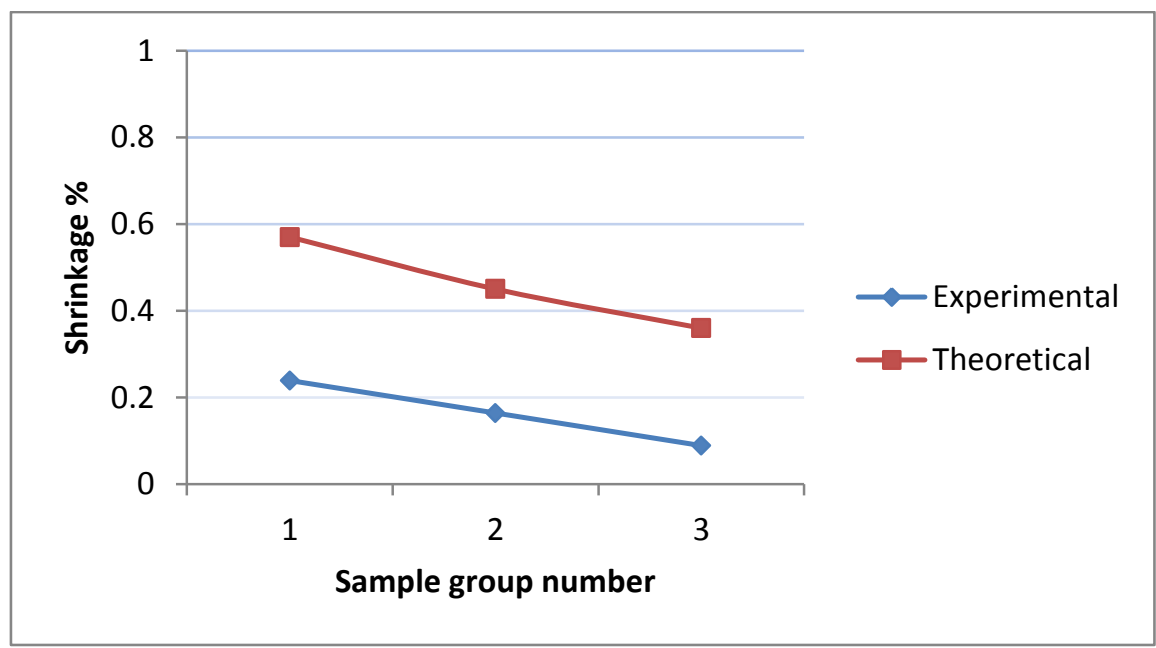

Figure 10. Experimental and theoretical shrinkage. 


\section{CONCLUSIONS}

In this study the effect of the cavity pressure on the part quality was investigated through a mathematical and experimental work. The flow marks as a part of the plastic part defects was studied by introducing a relation between the injection flow rate and the filling distance with the filling pressure on a disk shape product. An efficient frontier had been done to optimize the warpage and the shrinkage defects simultaneously. Experimental validation was carried out and the results showed that:

1- There are no flow marks on the surface of the product after using the proposed variable filling pressure profile.

2- The effect of the warpage increases with increasing the packing pressure. The average deviation between predicted and experimental results of the warpage was $0.035 \mathrm{~mm}$. This value is better than the general flatness tolerance [0.1 $\mathrm{mm}]$ according to ISO1101:2004 standard for geometrical tolerancing.

3- The effect of shrinkage decreases with increasing the packing pressure. The highest value of the shrinkage was $0.23 \%$. This value is less than the typical value for this material [ $\leq 0.44 \%$ ] according to ASTMD955 and ISO 294-4 [15].

4- The efficient frontier that obtained can be used as an indicator and a guide in compromising the warpage and the shrinkage with the packing pressure. This is a powerful tool for weighing the cost of improving one aspect versus the other one.

\section{REFERENCES}

[1] Soon Chun Kuek. "An investigation of cavity pressure as a process and quality indicator in the micro-injection molding process". PhD thesis, Faculty of Mechanical engineering, Clemson University, 2007.

[2] B. Pramujati, R. Dubay, and C. Samaan. "Cavity pressure control during cooling in plastic injection molding". Advances in Polymer Technology, 25(3):170--181, 2006.

[3] Mohd Nazri Bin Noordin. "Sink mark defect on injection molding using different raw material". PhD thesis, Faculty of Mechanical Engineering -- University of Malazya Pahang, 2009.

[4] S. J. Liao, D. Y. Chang, H. J. Chen, L. S. Tsou, J. R. Ho, H. T. Yau, W. H. Hsieh, James T. Wang, and Y. C. Su. "Optimal process conditions of shrinkage and warpage of thin-wall parts". Polymer Engineering \& Science, 44(5):917-928, 2004.

[5] Natti S. Rao and Günter Schumacher. "Design formulas for plastics engineers". Cincinnati, 2Nd edition, 2004.

[6] Johon Bizzoli. "Intensification Ratio (Ri). What is it? And How to Calculate". Plastic Technology, 58:22-23, 2012.

[7] Tuncay Erzurumlu and Babur Ozcelik. "Minimization of warpage and sink index in injection-molded thermoplastic parts using taguchi optimization method". Materials \& Design, 27(10):853 - 861, 2006. 
[8] Takaaki Matsuoka, Jun-Ichi Takabatake, Akihiko Koiwai, Yoshinori Inoue, Satoru Yamamoto, and Hideroh Takahashi. "Integrated simulation to predict warpage of injection molded parts". Polymer Engineering \& Science, 31(14):1043--1050, 1991.

[9] Yuehua Gao, Lih-Sheng Turng, and Xicheng Wang. "Process optimization and effects of material properties on numerical prediction of warpage for injection molding". Advances in Polymer Technology, 27(4):199--216, 2008.

[10] Hasan Kurtaran. "Efficient warpage optimization of thin shell plastic parts using response surface methodology and genetic algorithm". The International Journal of Advanced Manufacturing Technology, 27(5-6 5-6):468-472, 2006.

[11] Abdullah Konak, David W. Coit, and Alice E. Smith. "Multi-objective optimization using genetic algorithms: a tutorial". Reliability Engineering \& System Safety, 91(9):992 - 1007, 2006.

[12] Du-Soon Choi and Yong-Taek Im. "Prediction of shrinkage and warpage in consideration of residual stress in integrated simulation of injection molding". Composite Structures, 47(1--4):655 - 665, 1999.

[13] Yuehua Gao and Xicheng Wang. "Surrogate-based process optimization for reducing warpage in injection molding". Journal of Materials Processing Technology, 209(3):1302 - 1309, 2009.

[14] Stanly Brown. "How big a sample do i need?". Tompkins Cortland Community College, 2007.

[15] ASTM International. "Standard test method of measuring shrinkage from mold dimensions of thermoplastics". Standard D955, ASTM, West Conshohocken, PA, 2008. 